DOI: https://doi.org/10.17648/2238-037X-trabedu-v29n1-16299

(c) (1) https://creativecommons.org/licenses/by/4.0/

\title{
A ATUALIDADE HISTÓRICA DA CATEGORIA POLÍTICA NA ONTOLOGIA DE LUKÁCS ${ }^{1}$
}

Historical news of the political category in Lukacs ontology

TRIGINELLI, Daniel Handan² JESUS, Sara Tatiane de ${ }^{3}$

\begin{abstract}
RESUMo
O presente trabalho surge como resultado do projeto de pesquisa "A Categoria Política em 'Para uma Ontologia do Ser Social', de György Lukács", financiado pelo Programa Institucional de Apoio à Pesquisa (PAPq-UEMG), no qual se analisou a obra do filósofo húngaro György Lukács, sendo Para uma Ontologia do Ser Social, em especial, o capítulo dedicado ao estudo sobre "O ideal e a ideologia", além do suporte de outras fontes. Não obstante, pretendeu-se compreender a importância da categoria política no que diz respeito ao desenvolvimento histórico humano, ou seja, o esforço em contribuir para a atualização da compreensão e influência que ela apresenta no desenvolvimento do ser social em seu processo contínuo de reprodução. Na mesma direção, almejou-se apreender os efeitos que os desdobramentos que esta categoria, a política, promove no momento histórico atual em que estamos inseridos, pois, através dessa análise, verificaremos que a humanidade se encontra diante da hegemonia da ordem do capital.
\end{abstract}

Palavras chave: Trabalho. Ideologia. Política.

\section{Abstract}

The present work arises as a result of the rese arch project "The Political Category In 'For An Ontology Of Social Being' by György Lukács" funded by the Institutional Research Support Program (PAPqUEMG), which analyzed the work of the Hungarian philosopher György Lukács,: For an Ontology of the Social Being, in particular, the chapter devoted to the study of "The ideal and ideology", in addition to the support of other sources. Regardless of, it was intended to understand the importance of the political category, with regard to the historical human development, that is, the effort to contribute to the updating of the understanding and influence that it presents in the development of the social being in its continuous process of development - reproduction. In the same direction, it was intended to apprehend the effects that the developments that this category, the policy, promotes in the current historical moment in which we are inserted, because through this analysis we will verify that humanity is facing the hegemony of the order of capital.

Keywords: Work. Ideology. Politics.

\footnotetext{
${ }^{1}$ O presente artigo apresenta os resultados alcançados pela pesquisa "A Categoria Política em 'Para Uma Ontologia do Ser Social', de György Lukács", financiado pelo Programa Institucional de Apoio à Pesquisa (PAPq-UEMG), ao qual agradecemos o estímulo e financiamento desta pesquisa.

${ }^{2}$ Historiador pelo Centro Universitário de Belo Horizonte (UNI-BH), mestre e doutor em Educação pelo Programa de Pós-graduação Conhecimento e Inclusão Social, da Faculdade de Educação da UFMG (PPGE/FaE/UFMG), Pós Doutor em Serviço Social Pela Universidade Federal de Juiz de Fora (UFJF), Professor no curso de História da Universidade do Estado de Minas Gerais, unidade Divinópolis (UEMG/Divinópolis) e coordenador do projeto supracitado. E-mail: daniellic.bchistoria@yahoo.com.br

${ }^{3}$ Graduanda do último período ( $\left.8^{\circ}\right)$ do curso de História, bolsista de Iniciação Científica do Programa Institucional de Bolsas de Iniciação Cientifica (PAPq-UEMG). E-mail: sarastatiane22@gmail.com
}

Trabalho \& Educação | v.29 | n.1 | p.139-154 | jan-abr | 2020 


\section{INTRODUÇÃO}

O texto apresenta os resultados alcançados pelos desdobramentos da pesquisa "A Categoria Política em 'Para Uma Ontologia do Ser Social', de György Lukács”. A referida pesquisa sustentou como objetivo a realização da análise da obra Para uma Ontologia do Ser Social, do filósofo húngaro György Lukács. A investigação deu especial atenção ao capítulo dedicado ao estudo sobre "O ideal e a ideologia", além de outras fontes que embasaram o estudo. Com esta pesquisa, pretendeu-se compreender e atualizar a importância da categoria política no processo de desenvolvimento histórico humano.

Para alcançar os objetivos acima apresentados, foram utilizados o procedimento marxiano de leitura e a análise imanente. Este procedimento consiste em apreender, compreender e reproduzir, com o máximo rigor, o ser por ele mesmo. Isso quer dizer que o conhecimento só pode ser extraído do próprio objeto e, só posteriormente, ser sistematizado. Ou seja, a possibilidade de conhecer está no momento primário, o ontológico, conhecer o ser por ele mesmo. A produção do conhecimento no sentido de preservar e registrar esse conhecimento é feita na sua sistematização, no momento secundário desse processo, o epistemológico, momento da síntese, do registro, da sistematização do apreendido e compreendido. Sendo assim, são as propriedades intrínsecas do ente que permitem apreender, compreender e reproduzir o conhecimento com máxima exatidão.

Marx (1999) confrontou a predominância puramente epistemológica na produção do conhecimento, subordinando o momento da epistemologia ao momento primário da ontologia. Neste sentido, a totalidade do ser social é o conjunto de complexos categoriais que se desenvolvem no transcurso da história pela ação humana. Ou seja, para ele, não é a razão, o pensamento humano que organiza a realidade, mas, ao contrário, é a realidade que forma e organiza o pensamento. Conforme o autor:

O concreto é concreto porque é a síntese de muitas determinações, isto é, unidade do diverso. Por isso, o concreto aparece no pensamento como o processo de síntese, como resultado, não como ponto de partida, ainda que seja o ponto de partida efetivo e, portanto, o ponto de partida também da intuição e da representação. (MARX, 1999, p. 39-40).

Chasin (2009, p. 12) lança luz sobre a questão que envolve a produção do conhecimento segundo o procedimento marxiano quando explica e reafirma o filósofo alemão ao afirmar que "a questão do saber em Marx está categorialmente subordinada à dilucidação ôntica, ao exercício da escavação pelo ser das coisas, e se resolve na ontologia".

Lukács, em Para uma ontologia do ser social, reproduziu uma síntese que vai desde o processo que apreende a autoconstituição do ser social até o desenvolvimento das mais complexas estruturas da totalidade social. Tomada a autoformação, "passa as determinações desse ser como ente que se põe no mundo, explicitando todos os nódulos internos que formam a plataforma necessária de domínio da natureza pelo complexo do trabalho através de seus pores teleológicos". Ao verificar a correção dos resultados proporcionados pelo procedimento marxiano, Lukács analisa, de forma imanente, o processo de surgimento e desenvolvimento dos complexos categoriais sociais. Ele faz este movimento tomando como ponto de partida o salto ontológico. Ou seja, o evento transformador, que só se tornou possível pelo desenvolvimento do complexo primário, o trabalho. O desdobramento deste complexo, como consequência, 
possibilitou o surgimento dos demais complexos sociais, cujos exemplos são a linguagem, a consciência e o direito. Nosso filósofo também apresenta, com o rigor necessário, os "pores teleológicos secundários a influência de um ou mais homens a realizarem pores traçados por outros homens e a divisão social do trabalho". Considerando uma criteriosa apreensão e compreensão destes processos, trata e reproduz o desenvolvimento estrutural das formas de reprodução social, desde as formas mais primitivas de agrupamento humanos, promove uma densa análise da Antiguidade da mesma forma que se debruça sobre a reprodução estruturada pelo sistema de produção feudal até alcançar o desenvolvimento das formas mais implicadas e complexas de categorias sociais, que só poderiam se desenvolver e progredir quando da "superação do feudalismo pelo capitalismo". (TRIGINELLI, 2016, p. 321).

No atual momento histórico, o modo de organização social, pautado pelas relações sociais do capital, em sua forma mais desenvolvida, o capitalismo, se impõe como "unipolar". Tal forma alcançou esta condição pela derrocada das experiências chamadas de socialismo real, em especial após a queda do muro de Berlim em 1989. Porém, é preciso pontuar que aqui se parte do pressuposto e da concordância da compreensão, que apontam um grau elevado de ocorrências e equívocos fundamentais acerca das experiências soviéticas, o que, de antemão, não refuta as teses marxianas. Ao contrário, essas experiências as reafirmam e apresentam sua validade como instrumento de apreensão e compreensão rigorosa da realidade. Neste sentido, existe consenso ao entendimento exposto por Souza Junior (2011b) quando ele explicita que:

\begin{abstract}
A revolução humana, universal, provavelmente não se realizaria na emancipação política, mas pela emancipação social. Para se efetivar a revolução, seriam necessárias determinadas condições materiais objetivas, que organizariam e proporcionariam as condições subjetivas. Nessa ordem de reflexão, a história hoje nos comprovaria como as condições materiais são absolutamente necessárias. Tomando como exemplo o ator principal do amplo quadro dos países que amargaram as consequências dos erros de suas revoluções - a União Soviética - poderíamos concluir que a revolução russa teria atingido o patamar de uma emancipação política efetivada sem a base material necessária, e teria perdido desde logo a condição de efetivar a emancipação social. O que hoje ocorre mundialmente não seria, portanto, um desmentido de Marx, mas sua reafirmação: a emancipação social não se realiza sobre um quadro de miséria. Não houve, consequentemente, transição para a emancipação social nos países do Leste. (SOUZA JUNIOR, 2011, p. 7).
\end{abstract}

Ao retornar, de maneira imanente, aos textos originais de Marx, Lukács apreende e compreende de forma criteriosa o desenvolvimento filosófico-teórico-científico marxiano. Esta elucidação Ihe possibilita fazer, com extremo rigor, a apreensão e compreensão exata da realidade social existente no interior do movimento comunista de sua época. É neste processo que ele consegue ampliar o leque de elementos, que, à sua disposição, Ihe permitem promover análises críticas mais densas e fecundas do sistema capitalista, predominante em parte do mundo, bipolarizado até finais da década 1980.

Nos estudos dos originais marxianos, o filósofo húngaro tem o mérito de identificar o desenvolvimento e o aprofundamento das elaborações filosóficas efetuadas por Marx em seus textos de juventude, em especial, nos Manuscritos econômico-filosóficos, de 1844. Segundo Lukács, as bases do desenvolvimento da filosofia e da cientificidade marxiana estavam germinadas no texto citado, o que, mais adiante, Ihe permitiu promover, com extremo rigor, a crítica à Economia Política, em especial em sua obra da maturidade, $\mathrm{O}$ Capital. (TRIGINELLI, 2016, p. 320-321). 
Atualmente, as condições materiais necessárias à satisfação das necessidades humanas estão postas na esfera da realidade social. No processo de desenvolvimento histórico, as forças produtivas alcançaram um estágio suficiente de conquistas em relação à diminuição do tempo de trabalho socialmente necessário. Isso, em escala capaz de propiciar o ambiente satisfatório ao adequado ato de revolucionar as relações e condições sociais no sentido de transformar a sociedade e emancipar o trabalho. Entretanto, a "ausência de alternativa" ao atual estágio do capitalismo impõe, no interior das sociedades, a impossibilidade de alcançar a sobreposição de ordem ideológica. Isso fica claro com a predominância do discurso, em todas as camadas sociais, que defende a ideia de que qualquer alternativa divergente da lógica societária do capital não passa de utopia. Ou seja, a luta de classes, diante da perspectiva enunciada, já não existe e tratá-la, portanto, não faz o menor sentido. Ao emplacar este discurso, são proclamados o "fim" das classes sociais e o fim das possibilidades de mudança da estrutura social. Em outras palavras, o fim da história pelo advento da sociedade da informação ou conhecimento, pós-industrial.

Os marcantes fatos históricos no final de década de 1980, particularmente em 1989, com a queda do muro de Berlim, e, posteriormente, com o colapso ou a derrocada do pretenso "socialismo real", geraram, de um lado, o ufanismo apologético de uma ordem mundial "unipolar", ressuscitando as teorias conservadoras ou neoconservadoras (neoliberais), mascarando a mais profunda crise do capitalismo no final do século $X X$; de outro, decretaram o fim da possibilidade de uma alternativa ao capitalismo e das teorias que sustentam essa alternativa. Postulam-se, dentro desta significação, "o fim da história", "o fim das ideologias", "das utopias", "das classes sociais", consequentemente, o fim do proletariado e a emergência da "sociedade pós-industrial", "da sociedade da informação" ou da "sociedade do conhecimento", em que o trabalho já não seria o centro. O atual momento histórico em que nos movemos, ao contrário da aparente evidência e clareza, é opaco, reificado e fetichizado. Novos personagens e "novas máscaras" movem-se nas relações sociais capitalistas, de sorte que a violência do capital e das relações de classe obscurece, cada vez mais, seu fundamento. A ideia de revolução tecnológica e os conceitos de sociedade do conhecimento, sociedade da informação (não mais sociedade de classe), formação de competências, formação polivalente e flexível, qualidade total e empregabilidade, em planos diversos, prestam-se a ampliar a fetichização e os processos de crescente mercantilização e mercadorização da educação, constituindo-se em novas formas de exploração da força de trabalho. (SOUZA JUNIOR, 2008, p. 164-5).

A "nova" forma de organização social, acima anunciada, portanto, está pautada sobre os interesses postos a favor da fetichização do conhecimento e sua contínua utilização nos processos mercantis, sendo transformados em mercadorias e constituídos em razão da predominância de interesses econômicos e políticos presentes na sociabilidade capitalista. "Os novos tempos impõem transformações na base técnica, econômica, política, nas relações sociais, sendo, portanto, outros os requerimentos à formação dos indivíduos, largamente apregoados pelos chamados 'novos paradigmas educacionais"'. (SOUZA JUNIOR; 2008; p. 166). Em relação a isso, Mészáros reforça esta compreensão, afirmando que:

as teorias da "modernidade" e da "pós-modernidade" preenchem as exigências ideológicas das circunstâncias de conflito mais agudo. Ambas evitam fazer suas proposições teóricas fundamentais considerando uma dada situação histórica. As referências aos processos sociais existentes parecem mais observações ilustrativas ocasionais do que parte essencial da própria teoria. Não há conexão inerente entre o discurso teórico geral e o "mundo da atividade concreta" de uma dada ordem sócio-histórica. (MÉSZÁROS apud SOUZA JUNIOR, 2008, p. 175). 
A síntese do movimento feito pelo capital apresentado acima somente pode se efetivar como resultado na dimensão social da política. Antes de prosseguir, faz-se necessário demarcar que, por político, parte-se da apreensão e da compreensão que se faz da reprodução marxiana. Sendo assim:

A política é, segundo Marx, uma atividade meio, datada historicamente e instrumental. É algo que há de ser superado. Esta concepção da política recusa o entendimento de que ela constitui uma dimensão do humano e do social de forma permanente e estrutural. Marx recusa as elaborações que se pautam na busca da perfectibilidade da política, compreendida como algo inerente à essência do social, portanto, finalidade última da objetivação plena do ser social. A finalidade política é sempre parcial e inacabada frente à possibilidade humana da emancipação das condições materiais que envolvem a apropriação privada dos frutos do trabalho humano. (SOUZA JUNIOR E TRIGINELLI, 2017, p. 271).

E tal resultado político é conquistado pela superposição de classe que se impõe pelo papel mediador exercido pelo Estado na relação antagônica envolvendo capital e trabalho. Neste sentido, para o Estado não cabe e, em tese, não será feita distinção em razão de nascimento, preparação para a execução de atividade de trabalho, ou posição social política. Ao fazer isso, o Estado declara cada membro da sociedade como participante em pé de igualdade das atividades que conferem soberania ao país. Essa estrutura não impede que o Estado disponha de autorização para que as posições e atividades citadas acima sigam seu fluxo de desenvolvimento próprio e, assim, se "tornem efetivas à sua essência particular". Aliás, ela é a condição fundamental que determina a necessidade de um Estado mediador e regulador das condições provenientes do desenvolvimento dessa essência particular, sendo essa a condição necessária para o Estado constituir sua condição universal. "Isso mesmo! Só assim, pela via dos elementos articulares, é que o Estado se constitui como universalidade". (MARX, 2010, p. 40).

Nesta forma de Estado, toda a mesquinhez do individualismo burguês se faz presente na área externa à estrutura estatal, subsistindo com a forma reguladora do Estado que medeia essa contradição. Porém, essa forma de organização social, além destes elementos, agrega em si as "qualidades da sociedade burguesa". Nesse sentido, "o Estado político constitui, por sua essência, a vida do gênero humano em oposição à sua vida material". (MARX, 2010, p. 40).

Marx afirma que nos lugares onde o Estado alcançou sua forma política madura, definitiva, as pessoas tomam como característica a condução de uma vida dupla, que extrapola o campo da subjetividade psíquica e abrange, também, a realidade de sua vida real, concreta. Isso pode ser verificado ao se constatar que as pessoas mantêm uma vida celestial e uma vida terrena, desempenham um papel na vida política, onde se reconhecem como um ser que atua em comunidade, e, igualmente desempenham outra atividade na esfera da vida burguesa, cuja atuação se dá no campo da individualidade, levando a reconhecer os demais como meios. Esta manipulação "degrada a si próprio à condição de meio e se torna um joguete na mão de poderes estranhos a ele". (MARX, 2010, p. 40).

Segundo Marx, "a relação entre o Estado político e a sociedade burguesa é tão espiritualista quanto a relação entre o céu e a terra". Sendo assim, para o autor, a antítese entre as duas esferas é igual, pois o Estado político a sobrepuja, utilizando-se da mesma base com que a forma religiosa ultrapassa os limites existentes na estrutura de mundo profano. Isso significa que o Estado político forçosamente confere cópia e se permite ser 
dominado pela sociedade burguesa. "Na sua realidade mais imediata, na sociedade burguesa, o homem é um ente profano. Nesta realidade em que constitui para si mesmo e para outros um indivíduo real, ele é um fenômeno inverídico". (MARX, 2010, p. 40). Desta forma, no interior do Estado, por outro lado, se dá o espaço em que a pessoa "equivale a um ente genérico", ela se tomando uma sócia imaginária que compõe uma soberania ilusória pelo fato de ela ter sido retirada do campo individual de sua vida e ter sido posta nesse lugar vazio "com uma universalidade irreal". (MARX, 2010, p. 41).

Para Marx (2010, p. 41), todos os que professam uma "religião particular", em um contexto como o descrito, sofrem o conflito entre sua crença e sua cidadania. Igualmente, ele estabelece uma forma conflituosa contra os demais membros da sociedade e, por fim, "reduz-se à divisão secular entre o Estado político e a sociedade burguesa". Para o bourgeoist, viver no Estado é se manter constantemente em estado de aparência. Porém, somente por meio do sofismo é que os bourgeois de tipo judeu se mantêm na esfera do Estado. O mesmo pode se dizer sobre o citoyen ${ }^{5}$, que não abdica de sua condição de judeu, "mas essa sofística não é pessoal". Essas diferenças são as mesmas reconhecidas entre outras categorias de pessoas que atuam na sociedade, "o mercador e o cidadão, entre o diarista e o cidadão, entre o proprietário de terras e o cidadão, entre o indivíduo vivo e o cidadão". Neste sentido, não há diferença na contradição que se coloca nas esferas "entre o homem religioso e o homem político" e "entre bourgeois e o citoyen, entre o membro da sociedade burguesa e sua pele de leão política".

Ao conferir a seção em sua totalidade, Marx demonstra que, segundo a filosofia do direito de Hegel, a sociedade burguesa, com todas as suas contradições e antagonismos em relação ao Estado político, é declaradamente dada como necessária, da mesma forma como o Estado político também é reconhecido como necessário.

A emancipação política de fato representa um grande progresso; não chega a ser a forma definitiva da emancipação humana em geral, mas constitui a forma definitiva de emancipação humana dentro da ordem mundial vigente até aqui. Que fique claro: estamos falando aqui de emancipação real, de emancipação prática. (MARX, 2010, p. 41).

Marx esclarece que os homens alcançam a emancipação pela via política da religião, retirando-a da esfera do direito público, transferindo-a para o privado. Dessa forma, a religião desocupa o espaço de espírito do Estado, espaço em que as pessoas, de forma limitada, particular e específica, ainda mantêm um comportamento no interior da esfera do "ente genérico em comunidade" (MARX, 2010, p. 41) em relação com outras pessoas. Essa relação toma o lugar de espírito no interior da sociedade burguesa, que promove e estimula o egoísmo e a guerra dos homens, todos os homens contra todos os homens. "Ela não é mais a essência da comunidade, mas a essência da diferença". Essa forma de estrutura social culminou na desagregação das pessoas das comunidades das quais elas faziam parte, de si mesmo e como tinha sido em sua forma original. "Ela já não passa de uma profissão abstrata de perversidade particular, do capricho privado, da arbitrariedade". (MARX, 2010, p. 42). Sendo assim, Marx alerta para o perigo em não reconhecer os limites da emancipação política, pois:

A cisão do homem em público e privado e o deslocamento da religião do Estado para a sociedade burguesa não constituem um estágio, mas, sim, a realização plena da

\footnotetext{
${ }^{4}$ Pessoa que está inserida na sociedade burguesa.

${ }^{5}$ Cidadão em francês.
} 
emancipação política, a qual, portanto, não anula nem busca anular a religiosidade real do homem. (MARX, 2010, p. 42).

O que Marx (2010, p. 42) expressa acima é a passagem do homem religioso para a condição de cidadão, sendo concreta essa transformação na esfera real da sociedade. Trata-se, portanto, da emancipação política, não em uma forma de evitá-la, pois "ela representa o modo político de se emancipar da religião". Contudo, é preciso ressaltar que - Estado político se estabelece pelo uso da violência para se firmar como Estado político, tendo como pressuposto a sociedade burguesa. Nesse momento de convulsão, estabelece-se um Estado de "autolibertação humana" para tentar realizar-se por meio da autolibertação política. Nesse caso, o Estado tem por preceito, condição e deve fazê-lo, considerando a condição posta, no sentido de promover a abolição da religião, sendo necessário que ele avance até alcançar essa consequência, ou seja, efetivar a destruição da religião. Todavia, somente se esse movimento convulsivo conseguir alcançar o ponto máximo, quer dizer, a extirpação da propriedade privada em sua totalidade, valendo-se dos meios de violência, é que se pode deslumbrar o alcance da liberdade plena. "Nos momentos em que está particularmente autoconfiante, a vida política procura esmagar seu pressuposto, a sociedade burguesa e seus elementos, e constituir-se como a vida real, sem contradição do gênero humano". Porém essa possibilidade somente pode se estabelecer e se manter, caso ela mantenha a estrutura de violência permanentemente, o que conduz essa sociedade a estar em contradição com "suas próprias precondições de vida", o que quer dizer que é preciso sustentar a condição de uma revolução permanente. Em consequência dessa possibilidade, a ordem vigente se empenha em pôr fim ao drama político e em restabelecer a estrutura social burguesa em sua totalidade, dessa forma, mantendo a religião, a propriedade privada e os demais elementos que compõem a sua estrutura.

Conforme os elementos apresentados, compreende-se que, na atualidade, a essência da categoria política se mantém, principalmente em relação a seu caráter de classe. Contudo as formas assumidas por ela sofreram importantes transformações ao longo do desenvolvimento da ordem do capital, em especial, em sua forma mais desenvolvida, o capitalismo. Assim, o objetivo central proposto consiste em apreender, compreender e explicitar rigorosamente a essência que norteia a categoria política em seu processo de transformações históricas. Da mesma forma, pretende-se explicitar sua atual forma e procurar vislumbrar as possibilidades postas no sentido da superação de tal estágio do desenvolvimento societário.

\section{O TRABALHO}

O trabalho para Lukács é a categoria fundante de todas as outras categorias, pois somente através dessa categoria, o trabalho, é que as demais categorias surgem e se desenvolvem. Neste sentido, para o filósofo húngaro, o trabalho resguarda a prioridade ontológica no processo de formação e reprodução do ser social. E verificável que no trabalho existe a contínua efetivação de pores teleológicos, materializando a transformação do que se tem idealmente existente nas coisas, no mundo, ou seja, partindo da casualidade existente nas coisas transformadas, às quais, em si, a produção humana agrega valor de uso para a satisfação de suas inúmeras necessidades. Sendo assim, "o trabalho é uma unidade existente entre o pôr efetivo de uma dada objetividade e a atividade ideal prévia diretamente mediada e voltada para a realização de uma finalidade". (FORTES, 2016, p. 45). Sobre essa capacidade e vantagem determinante existente no ser social em relação aos outros seres naturais, Lukács cita Marx para 
delimitar o fundamental papel que a teleologia opera no interior do trabalho transformador humano na citação que compara o trabalho da abelha ou da aranha ao trabalho do homem.

No ato de trabalhar, o ser deixa sua condição puramente biológica e se eleva a um estágio superior de existência, ou seja, o salto ontológico, a passagem do indivíduo do estágio primitivo para o ser social, que se dá através da categoria trabalho. Sendo assim, o indivíduo se autoconstitui como ser que se põe no mundo e o transforma, ao mesmo tempo que a si próprio, pois no processo de transformação da natureza e nas inúmeras alterações que nela ocorrem, o indivíduo se ressignifica, se transforma e se reinventa mediante os processos de transformação do mundo. Lukács identifica, mesmo reconhecendo que não há como datar quando o ato em si acontece, por meio do desenvolvimento de estudos que demonstram os traços civilizatórios deixados pelas civilizações anteriores, elementos que possibilitam elucidar o percurso da construção material e social do mundo humano. Desse modo, evidencia-se a categoria que tem em si a prioridade ontológica, o trabalho:

através dele realiza-se, no âmbito do ser material, um pôr teleológico como surgimento de uma nova objetividade, de forma que o trabalho se torna modelo de toda a práxis social, na qual, com efeito - mesmo que através de mediações às vezes muito complexas -, sempre se realizam pores teleológicos, em última análise, de ordem material. (LUKÁCS, 2013, p. 47).

Ao seguir Marx e submeter o pôr teleológico ao trabalho, Lukács analisa como a ontologia marxiana, pautada no materialismo histórico, promove uma inflexão que coloca sobre seus pés as várias incompreensões das filosofias anteriores, casos de Hegel e Kant. Essas incompreensões sobre o pôr teleológico no trabalho, no interior desse processo de desenvolvimento, encobrem a prioridade ontológica da categoria mediadora da relação entre o humano e a natureza e, portanto, o processo de autoconstituição do ser por si mesmo.

Lukács, ao tratar do trabalho como a realização de pores teleológicos que promovem a ação e realização humana e se efetiva na natureza e a transforma, demonstra que, nesse ato, está contida a gênese efetiva promotora da formação humana. Isso porque tal processo desencadeia o desenvolvimento necessário à autoconstituição do ser social. (TRIGINELLI, 2016, p. 86).

Dessa forma, Lukács deixa claro que, no desenvolvimento humano, estão presentes tanto a objetividade quanto a subjetividade, atuando ambas de maneira contínua no interior dos desdobramentos presentes, tendo como referência do complexo originário, os pores teleológicos.

Por essa razão, o trabalho é reconhecido como princípio que conduz à humanização do indivíduo, que se torna base para um futuro desenvolvimento de todos os demais complexos categoriais que compõem a totalidade ontológica real singular do ser social, sobrelevando-o à sua condição natural, desencadeando, dessa forma, a potencialidade humana. (TRIGINELLI, 2016, p. 87).

Conforme o trabalho se consolida como resultado e os acúmulos de conhecimentos adquiridos na natureza, algumas práticas vão sendo aplicadas a outras transformações, para as quais essas técnicas não foram originalmente elaboradas, ou seja, se recriando e se reinventando. Com isso, vai se consolidando, gradativamente, de maneira relativa, uma autonomia, que vai se generalizando e se fixando sob "observações que já não se 
referem de modo exclusivo e direto a um único procedimento" (LUKÁCS, 2013, p. 86); ao contrário disso, vão acumulando elementos que permitem promover determinada generalização segundo os fenômenos que ocorrem na natureza em geral. "Essa consciência se torna certamente sempre mais difusa, sempre mais autônoma e, no entanto, continua ineliminavelmente, embora através de muitas mediações, em última análise, um instrumento de reprodução do próprio homem". (LUKÁCS, 2013, p. 87).

Por meio de Lukács, percebemos que no percurso do desenvolvimento material histórico, considerando o complexo do trabalho, foram surgindo novas categorias, que se apresentavam como mais complexas e superiores às demais. Porém não se pode perder a dimensão de que, nesse processo de surgimento e sobreposição das categorias, essas categorias inferiores se mantêm na base fundante material de sua existência, de forma que isso é o que ocorre e coloca em movimento a relação entre natureza orgânica e inorgânica, ou na relação que o ser social estabelece com essas duas formas do ser natural. Não obstante, é explicitado o esforço de Lukács em demonstrar como, pelo trabalho, surgem novos complexos de categorias e também novas funções no processo de objetivação. Ou seja, ele aponta a necessidade de compreender que as mudanças ontológicas são promovidas pelo salto do ser biológico ao social no campo que abrange o comportamento do indivíduo.

Todas as categorias que fundamentam uma primazia no modo de agir humano em relação à natureza e na relação que os homens estabelecem entre si têm necessariamente por pressupostos esse complexo, sua estrutura, o modo de seu ordenamento e a articulação de suas categorias. (FORTES, 2001, p. 85).

Os pores teleológicos primários atuam de forma direta sobre um determinado objeto ou elemento natural, de forma que os pores teleológicos secundários já têm como finalidade a consciência de outros homens, ou seja, "não são mais intervenções imediatas sobre objetos da natureza, mas intencionam provocar estas intervenções por parte de outras pessoas". (FORTES, 2007, p. 3). A compreensão dos atos do pôr teleológico secundário nos dá a base para a compreensão do processo de desenvolvimento das fases "superiores da sociabilidade, cuja gênese pode ser encontrada na forma originária do trabalho" (FORTES, 2007, p. 3), pois a dinâmica, que é inerente às interações categoriais do trabalho, não apenas instaura a origem humana como também determina a dinâmica das formas superiores da prática social de seus indivíduos. Os pores teleológicos secundários ocupam lugar de destaque, assumindo papel importante na dinâmica deste processo.

\footnotetext{
Estas formas de teleologia se tornam mais "desmaterializadas", uma vez que se desvinculam da relação direta com o momento material da prática laborativa. São elas que mais tarde darão origem a dimensões importantes da prática social, tais como a ética, a ideologia, e inclusive - e esta é uma questão crucial para Lukács - é por meio delas que podemos vislumbrar a gênese das ações políticas. Precisamente por isso, são também designadas por posições socioteleológicas. É importante fixar tal determinação: tanto as questões do trabalho quanto as da complexificação da dinâmica da sociedade humana, com o advento das formas superiores da vida social, são tratadas prevalentemente segundo a determinação recíproca e a superação da heterogeneidade entre teleologia e causalidade. Essas categorias formam, no interior das elaborações lukácsianas, a base analítica de toda e qualquer ação do ser social. (FORTES, 2007, p. 4).
}

Tendo em vista estes fundamentos iniciais apresentados por estudiosos do filósofo húngaro e pelo próprio Lukács de que todo o processo social é posto em movimento por meio das ações teleológicas individuais, mas que, em sua totalidade estes atos não têm 
uma finalidade exatamente determinada, resultando num movimento que opera por meio de "nexos causais espontâneos. Afirmação que nos leva, portanto, a entender que no plano da totalidade do ser social está presente toda uma malha de nexos que atuam sob a forma de uma "causalidade social". (FORTES, 2007, p. 4).

\section{IDEOLOGIA E POLÍTICA}

A exposição acima é o que permite a Lukács fazer o retorno e a análise imanente das possibilidades que permeiam a emancipação humana. Ao se debruçar sobre a práxis, 0 filósofo húngaro abstrai as categorias linguagem e direito, por serem distintas, com o objetivo de apreender a totalidade do desenvolvimento social, tanto na dimensão da espontaneidade (linguagem) quanto na dimensão que transcende o metabolismo dos homens com a natureza, a partir do momento em que eles constituem complexos de categorias de caráter social (direito). "Esse processo de constituição da vida social e do desdobramento de categorias cada vez mais sociais se estabelece desde o comunismo primitivo, que se dá pelo desenvolvimento do complexo econômico que pauta a vida social". Contudo, naturalmente, neste processo, seu desdobramento não está condicionado ao desdobramento da realidade econômica. Isto quer dizer que, na totalidade, é posto igualmente o desenvolvimento de complexos extraeconômicos. "Isso porque, desde tempos imemoriais, os homens já necessitavam cooperar entre si”. Tendo essa necessidade como alicerce, inaugura-se a divisão do trabalho, fator que conduz os homens a realizar pores teleológicos secundários. "A unicidade que envolve as alternativas econômicas e extraeconômicas, as questões morais que envolvem o humano, em muitos casos não se apresentam de forma tão nítida, é o caso do trabalho como metabolismo com a natureza" (TRIGINELLI, 2016, p. 325). Ela somente pode demarcar o ponto de partida, apresentando-se como elemento que adiante torna possível o surgimento das sociedades de classes.

Nesse sentido, torna-se necessário compreender a política e sua relação com a ideologia, pois como nos alertam Vaisman e Fortes (2014, p. 120), "a política, para o pensador húngaro, constitui uma forma específica de ideologia", de forma que "a ideologia é, sobretudo, a forma de elaboração ideal da realidade que serve para tornar a práxis social humana consciente e capaz de agir". (LUKÁCS, 2013, p. 465).

\footnotetext{
Essa forma, que marcará todas as sociedades, pela dissolução do comunismo primitivo, precisa, em sua constituição, dos elementos ideológicos que se estabelecem pelo antagonismo entre as classes que se estabelecem no desenvolvimento histórico. Dessa maneira, é verificável, no decorrer da história, o papel desempenhado pelos indivíduos ou pelo conjunto deles, quando de sua assimilação (TRIGINELLI, 2016, p. 325).
}

Neste contexto, é necessário destacar nas representações estatais que a política desempenha um papel fundamental no transcurso do desenvolvimento social e de sua reprodução. Lukács expõe como o complexo e práxis da política, em sua gênese, é apreendido e entendido como mediador dos conflitos/antagonismos que envolvem as classes sociais. A princípio, este complexo não se caracteriza como mediador das relações econômicas, sendo assim, trata-se de um complexo puramente social que reserva a si a tarefa de mediar "os aspectos éticos, morais, sociais etc., que se interpõem no jogo de forças entre as classes". Todavia, no decorrer da história, verifica-se que esse complexo, que, em sua gênese, resguarda a imparcialidade e se apresenta como mediador, por fim, consolida-se como um pêndulo. Porém trata-se de um pêndulo sempre desequilibrado a favor de garantir a concentração de poder dentro das estruturas sociais, independentemente de qual regime político vigore. Se tal colocação estiver 
correta, a classe dominante concentrará em si o controle social. Por esta razão, o complexo do "direito, nesse caso, demarca exatamente esse objetivo de equivaler direitos iguais sobre bases desiguais, alcançando, dessa maneira, um reflexo distorcido da realidade" (TRIGINELLI, 2016, p. 326). Dito de outra forma, o direito limita-se a tratar os fenômenos, entretanto nunca é capaz de ir além, ou seja, de alcançar, apreender e compreender a essência. Lukács, se referendando na reprodução teórica marxiana, demonstra como o direito, na sociedade organizada e mediada pelo Estado e pelas dimensões política e econômica, cria equivalências de direitos não equivalentes. Diz Lukács:

Por exemplo, quando um capitalista se vale de trabalho assalariado na produção, ele compra (como faz qualquer comprador) o valor de uso, nesse caso, o da força de trabalho, de sua capacidade de produzir mais que o necessário para sua reprodução, exatamente a propriedade que determina o seu valor de troca. É a execução do trabalho - no quadro do tempo de trabalho socialmente necessário - que torna possível que os produtos criados por meio dele (igualmente valores de uso), por sua vez, adquiram um valor de troca, no qual está contido o produto específico do valor de uso da força de trabalho como mais-valor. (LUKÁCS, 2013, p. 167).

Contudo, em Lukács, a questão ideológica não está restrita à dimensão política e a seus processos de dominação social, trata-se de uma questão bem mais ampla, que engloba outras dimensões da sociabilidade, como a filosofia, a ciência, o direito e a política, entre outros. "A ideologia é antes de tudo um instrumento para obstruir conflitos surgidos no interior dos processos históricos do ser social, de forma que o que realmente determina se dado conjunto de ideias é ou não ideologia é sua função social, não seu caráter de falsidade". (VAISMAN E FORTES, 2014, p. 120-121). Desse modo,

a mais pura das verdades objetivas pode ser manejada como meio para dirimir conflitos sociais, ou seja, como ideologia, já que ser ideologia de modo algum constitui uma propriedade social fixa das formações espirituais, sendo, muito antes, por sua essência ontológica, uma função social, não um tipo de ser (LUKÁCS, 2013, p. 564).

E explicita as consequências:

Nem um ponto de vista individualmente verdadeiro ou falso, nem uma hipótese, teoria etc., científica verdadeira ou falsa constituem em si e por si só uma ideologia: eles podem vir a tornar-se uma ideologia, como vimos. Eles podem se converter em ideologia só depois que tiverem se transformado em veículo teórico ou prático para enfrentar e resolver conflitos sociais, sejam estes de maior ou menor amplitude, determinantes dos destinos do mundo, ou episódicos (LUKÁCS, 2013, p. 467).

Ainda de acordo com Vaisman e Fortes (2014, p. 124), a ideologia pode ser entendida na perspectiva luckasiana como algo que segue uma função social, "como formações ideais diversas sobre a base das quais os indivíduos organizam suas ações e reações ao mundo como forma de conscientizar e resolver os conflitos de seu meio social". Sendo assim, perde-se o imaginário ou "pré-conceito" de uma ideia da ideologia como conteúdo estático e imutável, com uma estrutura bem definida da atividade prática humana, "assim como a ideia da ideologia como atributo específico de elementos fixos da prática social, pois a ideologia constitui um momento ideal da ação prática dos homens", (VAISMAN E FORTES 2014, p. 124), de forma que qualquer reação ou até mesmo as respostas, sejam elas produzidas pela ciência, filosofia, religião, entre outros, construídas pelos indivíduos como forma de agir sobre os problemas impostos pelas determinadas situações do cotidiano, "podem se tomar ideologia, quando fornecem elementos e 
condições para conscientizar, orientar e operacionalizar a prática social cotidiana". (VAISMAN E FORTES, 2014, p. 124). Por isso,

Cumpre à ideologia a função de ordenar as decisões individuais, de coordená-las em um contexto da vida geral dos homens, no esforço de esclarecer a cada membro desta sociedade como é preciso e indispensável para a sua própria existência julgar e adequar suas decisões em conformidade aos interesses coletivos. Nas formas superiores da prática social, onde os conflitos entre as classes aparecem como elementos decisivos, a ideologia passa a se manifestar como aparato ideal por meio do qual os indivíduos, imersos em suas classes, enfrentam suas lutas sociais. Nessa manifestação histórica peculiar das sociedades de classes, a ideologia tem um sentido restrito (VAISMAN E FORTES, 2014, p. 122).

Lukács afirma que a ideologia "consiste em que os homens se tomem conscientes e, com a ajuda das ideologias, travem seus conflitos sociais, cujos fundamentos últimos devem ser procurados no desenvolvimento econômico" (LUKÁCS, 2013: 471). Ou seja, os indivíduos que almejam modificar as estruturas e suas ramificações de poder devem, antes de tudo, tornar-se conscientes, de forma que estejam cientes de suas potencialidades e também atentos às explorações postas pelo capital, pois somente através da autoconscientização por meio das ideologias, como aponta Lukács, é que os indivíduos estarão prontos para travar os conflitos sociais necessários, que desafiam a ordem vigente do capital, de forma que visem à transformação radical, no sentido de ir à raiz e transformá-la, das estruturas dominantes do capitalismo.

A política como forma específica de ideologia corresponde àqueles conjuntos de atividades e elaborações ideais por meio das quais os homens tomam consciência e enfrentam os conflitos que surgem na sociedade, pois o campo da política se constitui no âmbito do conflito e da ação social que envolve e atua sobre a totalidade da formação social. Sendo assim, Vaisman e Fortes (2014) afirmam que a política aparece como a prática, em última instância, dirigida à totalidade social, pois apenas pode agir sobre essa totalidade, sobre as diretrizes e tendências características dessa totalidade, atuando no plano da imediatidade, onde se põe em movimento:

[...] o mundo fenomênico social como terreno do ato de mudar, isto é, de conservar ou destruir o existente em cada caso; contudo, a práxis desencadeada desse modo inevitavelmente é acionada de modo mediado também pela essência e visa, de modo igualmente mediado, também à essência (VAISMAN, 1989, p. 502-503).

Desta forma, é possível identificar que a contradição em questão está presente na ordem social, desde as transformações sociais que levaram o ser social a pôr fim ao comunismo primitivo, até o momento do surgimento e predomínio das sociedades de classe, que se estendem à época atual, em todas as formas sociais conhecidas e verificadas no transcurso do desenvolvimento histórico. Desta maneira, facilita-se a tarefa de apreender, de maneira imediata, o antagonismo posto acerca das tomadas de posições nas esferas política, econômica e moral. Nesse caso, destaca-se que, por um lado, as tomadas de posições econômicas são baseadas em formas mais ou menos elaboradas pelo trabalho simples, já no que tange ao aspecto político e moral, a princípio, trata-se do resultado de algumas consequências advindas da esfera econômica que, por sua vez, propicia a ocorrência de efeitos na vida social, o que, em si, aparentemente prescreve determinantemente a estrutura resultante de uma contradição que envolve os valores.

É preciso ressaltar que o processo acima demarca a derrocada da ideia de unilateralidade acerca dos nexos sociais e econômicos que evolvem a atuação dos sujeitos. Em tal processo, a forma como os sujeitos concebem a realidade, o mundo, 
tomam suas decisões e estabelecem suas convicções são traços fundamentais que se estabelecem no transcurso de sua vida social que o ser social é um ser que responde, não se limita portanto a um ser que reage a condicionamentos externos. Por isso, como no trabalho, no contexto social os indivíduos atuam segundo escolhas que fazem diante das alternativas existentes e que são percebidas por ele ou são propriamente resultado de sua prática social. Torna-se possível compreender que os elementos de subjetividade, mesmo nas práticas econômicas, figuram como componentes secundários ou de segunda ordem no desenvolvimento do processo. Isso se dá pelo fato de que qualquer projeto ou necessidades que se apresentem antes do início de sua execução passam pelo crivo avaliativo do pôr, o que significa dizer que a decisão de execução ou não de quaisquer projetos fica a cargo da decisão dos sujeitos participantes.

O desenvolvimento da essência determina, portanto, os traços fundamentais, ontologicamente decisivos, da história da humanidade. Porém ela só obtém sua forma ontologicamente concreta em decorrência de tais modificações do mundo fenomênico (tanto da economia como da superestrutura); mas estas modificações só podem se concretizar como consequência dos pores teleológicos humanos, entre os quais também a ideologia ganha expressão como meio de enfrentar e resolver os respectivos problemas e conflitos. (LUKÁCS, 2013, p. 495).

A política e o direito, como elementos fundamentais do momento ideal, são elevados ao mesmo nível de importância que os demais elementos que compõem a objetiva realidade social. Nesse sentido, ficam demonstrados o inevitável vínculo e a relação destes polos no contexto da sociabilidade, que se desdobrou e segue em desdobramento no plano histórico. Nesse contexto, o pôr teleológico da política está fundando assim como o trabalho na indissociável relação entre subjetividade e objetividade. Ocorre que, tal como no trabalho, o pôr teleológico da política pretende um fim, sendo a ela posta uma finalidade para satisfazer uma necessidade ou resolver um conflito na dimensão social, ou seja, de maneira objetiva, ser capaz de influenciar os processos concretos do ser social. Um vasto terreno de alternativas é aberto diante dos sujeitos com base nos nexos causais presentes na objetividade da sociedade. Nesse caso, as decisões não são comportamentos mecânicos e determinados, ao contrário, são resultado de escolhas feitas pelo que está presente com contexto real. Essas escolhas podem representar a reprodução do que já está posto e, portanto, fazer seguir as coisas como estão, ou promover rupturas e mudanças na direção dos processos em curso. Fica entendido com isso que na práxis política está contida a relação contraditória representada pela unidade na relação estabelecida entre fenômenos e essência.

Do ponto de vista imediato dos pores teleológicos com intenção política, a união indissolúvel e a unidade de essência e fenômeno são tanto seu ponto de partida inescapável como seu fim necessariamente posto. Porém, justamente por causa dessa unidade imediatamente dada de essência e fenômeno, a práxis política é, em sua relação com a essência, que decide quanto à sua efetividade em última análise, mas só em última análise, uma práxis mediada. Por essa razão, essa forma imediata da unidade não anula as contradições existentes. Engels tem razão ao alegar que, nos casos singulares concretos, a política pode muito bem tomar um rumo oposto ao exigido pelo desenvolvimento econômico efetivo naquele momento, observando ainda com razão que, em tais casos, depois de fazer desvios, sofrer prejuízos etc., a realidade econômica acaba se impondo (LUKÁCS, 2013, p. 503).

E Lukács, na sequência, elucida a indissociável relação que abrange a essência e o fenômeno pela análise do que ele denomina de a relação entre a superestrutura jurídica que atende a práxis política em momentos de ocorrência de conflitos generalizados para 
propiciar soluções a tais conflitos que promovam impulsos à infraestrutura econômica pela reformulação positiva do sistema de direito.

Em casos de conflitos generalizados, a práxis política, muitas vezes, volta-se para uma reforma da superestrutura jurílica. Contudo, êxito ou fracasso dependem de se e como uma reformulação do sistema de direito positivamente vigente influencia a própria economia, se e como ela é capaz de, por esse desvio, promover aquele elemento positivo que, na economia, impulsiona para diante. Este é apenas um dos tipos de entrelaçamento entre os mundos da essência e do fenômeno (LUKACS, 2013, p. 503).

Na passagem citada, Lukács apresenta um dos principais critérios presentes na práxis política, o da eficácia sobre as decisões acerca das alternativas que o indivíduo opta por acatar. Como no trabalho, a categoria realização desempenha uma função decisiva, já que decisões acerca da eleição de determinadas alternativas que não cumpram eficientemente o papel de alterar os processos sociais findam em ser diminuída a condição de proposituras, de minúsculas subversões que não impulsionam potência suficiente para alcançar a malha que constituiu a própria realidade. As tendências relacionadas à essência apresentam um grande conjunto de determinações que, naturalmente, não precisam ser idealmente apreendidas na prática das ações políticas. A eficiência reside na inferência sobre os mais imediatos fenômenos sociais, causando, assim, interferência efetiva na direção seguida pela sociedade.

A práxis política de fato está direcionada simultaneamente para a unidade de fenômeno e essência da realidade social como um todo, mas só pode apreender essa realidade em sua imediatidade, o que ao menos comporta em si a possibilidade de que tanto o objeto intencionado como o objeto atingido pelo pôr teleológico permaneçam direcionados para o mundo do fenômeno que mais encobre e que revela a essência. Por essa razão, o fenômeno total da práxis política não seria esgotado se, durante a análise, sua efetividade imediata fosse considerada como critério exclusivo, embora ela inquestionavelmente constitua um momento importante e até indispensável da sua totalidade. Com efeito, uma resolução política, a concepção política que está na sua base etc., deixa de ser politicamente relevante quando lhe falta qualquer efetividade (LUKÁCS, 2013, p. 507).

Cabe reafirmar que, no processo aqui apresentado, a política, como uma ideologia, cumpre uma função social. Sendo assim, não se trata se tais ideias sejam verdadeiras ou falsas, mas se apresentam capacidade de alcançar de maneira eficaz e correta as sinuosidades do processo e dos nexos sociais objetivos. Sendo assim, verifica-se que a categoria estudada cumpre uma função decisiva para a reprodução do capital como parte decisiva na organização das sociedades. Isso é significativo no contexto atual, ou seja, do capitalismo, pois guarda uma diferença fundamental das sociedades anteriores. Lukács demonstra como as formas societárias que antecederam o capitalismo tendiam a promover o retorno à práxis política anterior. Por entender que o momento anterior era superior ou excelente, de forma fenomênica ou consciente, procurava-se fundamentar um movimento que oportunizasse "estar-voltando-para-trás". (LUKÁCS, 2013, p. 517).

Lukács, pelo contato com a reprodução da base material feita por Marx das sociedades que antecederam o capitalismo, foi convencido de que

O capitalismo é a primeira formação econômica, cujo processo de reprodução não tem um vínculo desse tipo com coisas passadas, no qual - pela primeira vez na história - os fins postos pelos pores teleológicos que perfazem a práxis política, segundo seu teor político, não podem ser direcionados para a restauração de algo passado, mas devem ser direcionados para a instauração de algo futuro (LUKÁCS, 2013, p. 517). 
Sendo assim, o capitalismo é um sistema de organização social datado historicamente e, portanto, sua existência não é natural, não é resultado de uma suposta natureza humana que faz o mundo ser a realização do capital como capitalismo. Ao contrário, sobre tal sistema social nada na história garante que ele seja eterno, ou seja, condição final no processo de reprodução humana. Ao contrário, o fato de surgir historicamente como a primeira formação econômica, cujos pores teleológicos seguem na direção de "instauração de algo futuro", aponta a possibilidade de estabelecer alternativas que possibilitem ir adiante e superar a própria ordem das coisas estruturadas e estabelecidas pelo capital. Nesse contexto, ideologicamente, a política é fundamental para o processo de reprodução do capital, assim como é importante para a realização concreta da alternativa ao capitalismo e a ordem do capital.

Longe de pretendermos esgotar toda a potência e profundidade da apreensão, compreensão e reprodução lukacsiana na totalidade da obra aqui estudada, retornamos à obra Sobre a questão judaica, ponto fulcral da obra marxiana, que oportunizou o processo empreendido por nosso filósofo acerca da categoria política. Ou seja, Lukács, na esteira de Marx (2010), toma como ponto de partida a cisão entre o citoyen e o sujeito privado. Isso quer dizer que, na sociabilidade do capital, a constituição da consciência e sua nova forma, resultado da economia capitalista, separam os sujeitos sociais em homme e citoyen, esse que faz com que os indivíduos reais somente sejam reconhecidos como humanos egoístas, sendo o verdadeiro ente humano somente encontrado no citoyen abstrato. Por fim, no contexto do capitalismo, a política se sobrepõe aos sujeitos peculiares, criando a abstração de esses indivíduos serem aqueles que gozam de igualdade no que tange às leis da sociedade, mas que são submetidos a condições absolutamente desiguais na dimensão da vida real.

\section{REFERÊNCIAS}

CHASIN. J. Estatuto Ontológico e resolução Metodológica. São Paulo/SP: Boitempo, 1ํ edição, 2009.

FORTES, Ronaldo Vielmi. As três determinações fundamentais da análise lukacsiana do trabalho: modelo das formas superiores, prioridade ontológica e abstração isoladora crítica da ideia da centralidade do trabalho em Lukács. Verinotio - Revista on-line de Filosofia e Ciências Humanas. n. 22. out./2016. Disponível em: http:/www.verinotio.org/conteudo/0.275012145075027.pdf. Acesso em: 21 maio 2020.

FORTES, Ronaldo Vielmi. Lukács e o desvelamento da perspectiva ontológica da obra de Marx. UNICAMP / CEMARX, 2007. Disponível em: https://www.unicamp.br/cemarx/anais_v_coloquio_arquivos/arquivos/comunicacoes/gt1/sessao6/Roanldo_Fortes.pdf. Acesso em: 21 maio 2020.

FORTES, Ronaldo Vielmi. Trabalho e Gênese do Ser Social na "Ontologia" de George Lukács. Dissertação (mestrado) - Universidade Federal de Minas Gerais, Departamento de Filosofia, Belo Horizonte, 2001.

LUKÁCS, György. Para uma ontologia do ser social II. Trad. Nélio Schneider. São Paulo: Boitempo, 2013. MARX, Karl. Sobre a questão judaica. Trad. Nélio Schneider, [trad. Daniel Bebsaïd, Wanda Caldeira Brant]. São Paulo: Boitempo, 2010. MARX, Karl. O Capital.

MARX, Karl. Para a crítica da economia política do Capital: O rendimento e suas fontes. Coleção Pensadores. Tradução de Edgard Malagodi e colaboração de José Arthur Giannotti. São Paulo/SP: Editora Nova Cultura LTDA, 1999.

SOUZA JUNIOR, Hormindo Pereira de. TRIGINELLI, Daniel Handan. Trabalho, Política, Formação e Emancipação Humana em Marx e Lukács. Revista Educação Temática Digital. Campinas, UNICAMP, vol. 19, n.1 p. 258 - 282, jan./mar. 2017. Disponível em: https://periodicos.sbu.unicamp.br/ojs/index.php/etd/article/view/8641638. Acesso em 21 maio 2020.

SOUZA JUNIOR, Hormindo Pereira de. A Política e a Emancipação Humana na Ontologia do Ser Social Marxiana: a emancipação social como única possibilidade de transitar para além do capital Marx e o 
Marxismo 2011: Teoria e Prática - Evento realizado pelo Núcleo Interdisciplinar sobre o Marx e o Marxismo (NIEP/MARX), Universidade Federal Fluminense - Niterói/RJ, de 28/11 a 01/12 de 2011, p. 1 a 8.

SOUZA JUNIOR, Hormindo Pereira de. Centralidade ontológica do trabalho ou centralidade da informação e do conhecimento nos processos de formação humana. Proposições Campinas/SP, v. 19, n. 2 (56), p. 163-179, maio/ago. 2008. Disponível em: http:/www.scielo.br/scielo.php?script=sci_artext\&pid=S0103-73072008000200012. Acesso em: 21 maio 2020.

TRIGINELLI, Daniel Handan. Trabalho e Formação Humana na Ontologia do Ser Social, de György Lukács. Tese (Doutorado em Educação) Faculdade de Educação ( $\mathrm{FaE})$ da Universidade Federal de Minas Gerais (UFMG), Belo Horizonte, 2016. Disponível em: https://repositorio.ufmg.br/handle/1843/BUBDAA2FZJ. Acesso em: 21 maio 2020.

VAISMAN, Ester \& FORTES, Ronaldo. A politicidade no pensamento tardio de György Lukács. Revista Estudos Políticos: publicação eletrônica semestral do Laboratório de Estudos Humanos (UFF) e do Núcleo de Estudos em Teoria Política (UFRJ). Rio de Janeiro, Vol. 5, N. 1, pp. 118-132, dezembro 2014. Disponível em: http://revistaestudospoliticos.com/. Acesso em: 21 maio 2020.

VAISMAN, Ester. A ideologia e sua determinação ontológica. Revista Ensaio, n. 17/18, 1989.

Data da submissão: 29/12/2019

Data da aprovação: 06/05/2020 